\title{
TUTORIA ACADÊMICA NO MESTRADO PROFISSIONAL: UM APRENDIZADO COMPARTILHADO
}

\author{
Marli Eliza Dalmazo Afonso de André (PUC-SP) * \\ Rodnei Pereira ** \\ Lisandra Marisa Príncepe ${ }^{* * *}$ \\ Elvira Godinho Aranha ${ }^{* * *}$
}

\begin{abstract}
RESUMO
O texto discute a tutoria acadêmica, atividade que faz parte da proposta curricular do Mestrado Profissional: Formação de Formadores, da Pontifícia Universidade Católica de São Paulo. Os tutores são doutorandos dos Programas de Educação da mesma Universidade. Por dois semestres, os tutores, com supervisão da coordenação do curso, acompanham os mestrandos no processo de desenvolvimento do seu trabalho final de Mestrado. Com o objetivo de analisar os significados que alunos e tutores atribuem à tutoria acadêmica, optou-se pela metodologia dos Núcleos de Significação (AGUIAR; OZELLA, 2006, 2013). Para a coleta de dados, utilizou-se um questionário contendo três perguntas abertas que foi encaminhado, via Google Docs, para 116 alunos e 13 tutores que participaram da tutoria nos anos 2013, 2014 e 2015. Um total de 45 discentes e todos os tutores preencheram o instrumento. Os resultados apontaram que a tutoria se constituiu num espaço de aprendizagem que possibilitou o desenvolvimento profissional para ambos os públicos. Essa atividade tem contribuído positivamente tanto para a formação de novos pesquisadores quanto de docentes e orientadores para a educação superior.
\end{abstract}

Palavras-chave: Cultura acadêmica. Tutoria acadêmica. Aprendizagem compartilhada. Núcleo de significação.

\section{ABSTRACT \\ ACADEMIC TUTORSHIP IN A PROFESIONAL MASTER COURSE: SHARED LEARNING \\ This paper discusses the academic tutorship, which is part of the curriculum in the Master Professional Course for Teacher Educators in the Pontifical Catholic University}

\footnotetext{
* Doutora em Psicologia da Educação pela University of Illinois, em Urbana-Champaign (USA). Coordenadora e professora do Mestrado Profissional em Educação: Formação de Formadores da PUC-SP. Professora do Programa de Estudos Pós-Graduados em Educação: Psicologia da Educação da PUC-SP. E-mail: marliandre@pucsp.br

** Doutorando em Educação: Psicologia da Educação pela PUC-SP. Professor de cursos de Licenciatura na Universidade Paulista (UNIP) e Faculdade do Educador (FEDUC). E-mail: rodneipereira@uol.com.br

*** Doutoranda em Educação: Psicologia da Educação pela PUC-SP. Professora de cursos de licenciatura na Universidade Paulista (UNIP) e Faculdade Sumaré. E-mail: lisandramprincipe@gmail.com

${ }^{* * * *}$ Doutora em Educação: Psicologia da Educação pela PUC SP. Coordenadora de curso na Faculdade do Educador (FEDUC). E-mail: elviraa@uol.com.br
} 
of São Paulo. Tutors are doctoral students in education at the same university. For two semesters, supervised by the head of the course, the tutors guide the graduate students to develop their final work of Master. In order to analyze the meanings that students and tutors attach to academic tutorship, we adopted the methodology of Meaning Nuclei (AGUIAR; OZELLA, 2006, 2013). To collect data, we used a questionnaire with three open questions that was sent via Google Docs to 116 students and 13 tutors who were involved in the tutorship in the years 2013, 2014 and 2015. A total of 45 students and all tutors filled the instrument. The results showed that tutorship is a learning space that enabled professional development for both audiences. This activity has contributed positively to both the learning and training of new researchers, as well as of prospective higher education teachers and advisers.

Keywords: Academic culture. Academic tutorship. Shared learning. Meaning nuclei.

\section{RESUMEN}

\section{TUTORÍA ACADÉMICA EN UN CURSO DE MAESTRÍA PROFESIONAL: UM APRENDIZAJE COMPARTIDO}

El texto analiza la tutoría académica, que es parte de la propuesta curricular de la Maestría Profesional: Formación de Formadores, en la Universidad Católica de Sao Paulo. Los tutores son estudiantes de doctorado de los programas de educación de la misma universidad. Durante dos semestres, tutores, bajo la supervisión de la coordinación del curso, acompañan los estudiantes graduados en el proceso de desarrollo de su trabajo final de Maestria. Con el fin de analizar los significados que los estudiantes y profesores atribuyen a la tutoría académica, usamos la metodología de Núcleos de Significación (AGUIAR; OZELLA, 2006, 2013). Para recopilar los datos, se utilizó un cuestionario con tres preguntas abiertas que se enviaran a través de Google Docs a 116 estudiantes y 13 profesores que participaron en la tutoría en los años 2013, 2014 y 2015 . Un total de 45 estudiantes y todos los tutores contestaron el instrumento. Los resultados mostraron que la tutoría constituye un espacio de aprendizaje que permitió el desarrollo profesional, para todos, estudiantes y tutores. Esta actividad ha contribuido de forma positiva tanto para el aprendizaje y la formación de nuevos investigadores, como para la formación de futuros maestros para la educación superior. Palabras claves: Cultura académica. Tutoría académica. Aprendizaje compartido. Núcleo de significación.

\section{Introdução}

O ingresso na vida acadêmica, seja nos cursos de graduação ou de pós-graduação, é marcado, na maioria das vezes, por um desconhecimento do estudante acerca das rotinas, modos de funcionamento das disciplinas e das culturas do escrito próprias do ambiente acadêmico.

Em um sistema educacional marcado por desigualdades, exclusão e seletividade como o brasileiro, é urgente e necessário discutir os desafios que envolvem a chegada de estudantes na pós-graduação. Esses estudantes que, de um modo geral, são produto do processo de democratização da educação nas últimas décadas, ingressam nos cursos de graduação sem um domínio das competências e saberes necessários para o exercício da vida acadêmica, o que aflige sobremaneira os professores do ensino superior que mencionam ser este um dos maiores desafios enfrentados em seu trabalho docente (PASSOS; PEREIRA; PRÍNCEPE, 2015). 
Em sua obra Os Herdeiros - os estudantes e a cultura, Bordieu e Passeron (2014) advertem que a inserção dos estudantes da classe trabalhadora na universidade precisa ser pensada pelas regras explícitas e não explícitas - do jogo universitário. Se não se prestar a devida atenção é provável que os sistemas de ensino reproduzam as desigualdades sociais "por meio do estabelecimento de uma relação estreita entre intelectuais (professores), educação e classes privilegiadas" (BOURDIEU; PASSERON, 2014, p. 9).

Essa afirmação, que pode ser perfeitamente transposta para o modo como são estabelecidas as relações nos cursos de pós-graduação, nos instiga, do ponto de vista ético-político, a pensar nos recursos pedagógicos e de avaliação que podem naturalizar certos privilégios sociais, reforçando a construção de relações e alimentando desempenhos baseadas em "méritos, dons e talentos individuais" (BOURDIEU; PASSERON, 2014, p. 9). Esses autores lembram, ainda, que "para uns, a aprendizagem da cultura da elite é uma conquista que se paga caro; para outros, uma herança que compreende ao mesmo tempo a facilidade e as tentações da facilidade" (BOURDIEU; PASSERON, 2014, p. 9). Sem que se desconsidere o processo de precarização do ensino superior, sobretudo privado, nas últimas décadas (SGUISSARDI, 2009), que justifica a baixa qualidade da formação oferecida aos estudantes deste nível de ensino, especialmente nas licenciaturas, desde a Reforma Universitária de 1968 (MARTINS, 2009), é importante acentuar que a inserção de egressos do ensino superior nos cursos de pós-graduação stricto sensu precisa ser vista com toda atenção.

$\mathrm{O}$ que se quer afirmar com isso é que as desigualdades sociais poderão ser facilmente reproduzidas pelos programas de pós-graduação se o ponto de partida for a demonstração de uma certa "prontidão" para as aprendizagens pelos estudantes, sem que seus conhecimentos prévios sejam devidamente considerados, pois pode ocorrer aquilo que nos adverte Valle (2014, p. 11):

[...] é por vias secretas, e amplamente legitimadas, que o sistema de ensino atua na fabricação de uma verdadeira 'aristocracia social', obscurecendo a dimensão meramente formal do princípio de igualdade de oportunidades, que está no funda- mento dos sistemas educacionais.

A origem social dos estudantes, assim como suas condições de vida e de trabalho, são variáveis que não podem deixar de ser consideradas, já que seus comportamentos e atitudes, durante a formação, serão constituídos pelas experiências forjadas nas/pelas referidas variáveis.

Em que pese o fato de os estudantes ingressantes na pós-graduação compartilharem a experiência de estudarem juntos, não se pode supor que todos terão experiências idênticas, nem desempenhos similares. Ao ingressar na pós-graduação, os estudantes enfrentam muitos desafios, sobretudo se pensarmos nos currículos, nos sistemas de cumprimento de créditos, na demonstração de proficiência em língua estrangeira, nas práticas de leitura e produção de textos acadêmicos e na relação com os orientadores. As habilidades que precisam ser desenvolvidas para a sobrevivência nessa etapa de estudos impõem desafios a serem enfrentados não só pelos estudantes, mas também pelos professores. Por isso, faz-se necessário encontrar estratégias que permitam contemplar as diferenças de repertório intelectual, linguístico, cultural com que os estudantes ingressam na pós-graduação, para que elas não sejam reforçadas, mas consideradas, de modo a possibilitar a todos os estudantes as ferramentas para o seu sucesso acadêmico.

Neste artigo, apresentamos uma estratégia desenhada para esta finalidade: trata-se de um processo de tutoria junto a estudantes do Programa de Mestrado Profissional em Educação: Formação de Formadores, da PUC-SP. Pretendemos, assim, discutir a experiência de tutoria acadêmica implantada no referido Mestrado Profissional, desde agosto de 2013, elegendo como foco principal os significados que alunos e tutores atribuem a essa experiência.

A relevância da discussão se estabelece na medida em que o modelo de tutoria implantado vem sendo avaliado positivamente pelos tutorandos, tutores e professores e vem sendo apontado como suporte fundamental no ingresso destes alunos na vida acadêmica, promovendo aprendizagens para todos os envolvidos.

Cabe considerar que o objeto de discussão do presente trabalho não se circunscreve aos modelos de tutoria virtual, em franca expansão e mais comum no campo da Educação a Distância, mas 
trata-se, sim, de uma experiência de tutoria presencial, sistemática, incluída na proposta curricular do curso.

Inicialmente, em busca de uma definição de tutoria, Arnaiz (2002, p. 15-16) lembra que há diversas definições possíveis para o termo:

O dicionário de língua define o tutor como um conselheiro ou guia de outro a quem serve de apoio. A. Lázaro e J. Asensi reúnem diferentes definições: 'É um professor [...] que se encarrega de atender diferentes aspectos que não são suficientemente tratados nas aulas' (Artigot). 'Tutor é o professor, o educador integral de um grupo de alunos' (Benavent). 'Pessoa que aconselha em tudo o que se refere à educação' (Schalmafus). 'A tutoria é uma atividade inerente à função do professor, que se realiza individual $\mathrm{e}$ coletivamente com os alunos de uma sala de aula, a fim de facilitar a integração pessoal nos processos de aprendizagem' (Lázaro e Asensi). 'A tutoria é a ação de ajuda ou orientação ao aluno que o professor pode realizar além de sua própria ação docente e paralelamente a ela' (S. Sánchez).

O conceito de tutoria que propomos neste trabalho aproxima-se das noções formuladas por Lázaro e Asensi e por Sánchez, já que empregaremos o termo tutoria acadêmica para designar todo o conjunto de ações de orientação pessoal e acadêmica desenvolvida por estudantes de pós-graduação mais experientes no processo de inserção de alunos ingressantes em um curso de Mestrado Profissional. Por ora, cabe explicitar, ainda, que compreendemos a tutoria como uma atividade sustentada pela aprendizagem entre iguais, entendendo que ela pode ser um importante recurso pedagógico, embora seja pouco explorado. Apoiados em Duran e Vidal (2007, p. 13), concordamos que:

Entre os recursos pedagógicos do século XXI não podem faltar os diferentes métodos de aprendizagem cooperativa que, baseando-se na diversidade e tirando proveito da mesma, permitem conceber [as interações educativas] como [parte de] uma comunidade de aprendizagem na qual as ajudas pedagógicas são proporcionadas entre todos os seus membros, sob a dinamização e a supervisão de professores.

Na pós-graduação, se nos dispusermos a enfrentar e construir modelos mais inclusivos, é necessário que possamos criar e utilizar diferentes estratégias e instrumentos que levem em conside- ração os conhecimentos prévios dos estudantes, a variabilidade e diversidade entre eles, bem como seus diferentes interesses e necessidades.

As práticas pedagógicas na pós-graduação, nesse sentido, clamam por inovações. Em nosso tempo, as práticas curriculares precisam se ocupar em pensar quais são os saberes necessários a todos e a cada um. Mais que isso, é preciso pensar em práticas que possibilitem a apropriação de tais saberes pelos estudantes, em um contexto em "que todos são cada vez mais diferentes" (ROLDÃO, 1999, p. 33). Apostamos, assim, na tutoria acadêmica como uma forma de valorizar a participação e a colaboração entre estudantes, bem como uma alternativa para fomentar a capacidade de cooperação, alinhavada pela valorização das diferenças existentes entre eles "como um elemento enriquecedor e de ajuda em nossa tarefa educativa" (DURAN; VIDAL, 2007, p. 14).

O princípio de valorização das diferenças nos é caro porque pensamos que sem heterogeneidade e sem diferenças a aprendizagem colaborativa não se edifica. A tutoria acadêmica, então, deve ter como fim que cada estudante aprenda com os outros e como valor o compromisso de cada estudante com a própria aprendizagem e com a de seus colegas.

Para discutirmos essa temática, e a fim de estabelecer as características específicas da experiência em foco, partimos de uma breve revisão da literatura pertinente ao assunto, tanto para expandir nosso conhecimento sobre experiências já realizadas, quanto para contribuir com o debate atual sobre o tema.

\section{Uma revisão de estudos sobre tutoria}

A fim de localizar as produções sobre o tema desse trabalho, realizamos uma revisão de literatura em sites de buscas nacionais e internacionais como: Scielo, Bireme, Lilacs, Banco de Teses da CAPES, Portal de Periódicos da CAPES/MEC e Google Acadêmico, utilizando os descritores "tutoria"; "tutoria pedagógica" e "mentoria" em quatro idiomas (português, inglês, francês e espanhol).

Assim, encontramos um conjunto de estudos no campo da Educação, sobretudo em língua inglesa, que se referem a programas de formação continu- 
ada de gestores escolares e professores, com base em modelos gerenciais e referenciais teóricos do campo da Administração.

Em língua francesa, a maioria dos trabalhos encontrados também se refere a processos de formação continuada de gestores e professores, ou ainda, de estudantes de licenciaturas. Em virtude disso, elegeu-se como descritor principal o termo "tutoria acadêmica", que ofereceu um considerável retorno de estudos em língua portuguesa e espanhola.

Limitando-nos aos periódicos científicos, encontramos 209 artigos. Após análise dos resumos, foram selecionados os que abordavam especificamente a tutoria acadêmica em pós-graduação, que totalizam seis trabalhos, todos publicados há menos de 10 anos, o que indica a novidade do tema.

Em um trabalho que se propôs a problematizar em que medida a pós-graduação no Brasil se compromete com a formação de docentes para o ensino superior, Bastos e colaboradores (2011) anunciam a escassez de programas voltados à formação docente no sistema de pós-graduação, bem como defendem que este deveria ser um espaço de desenvolvimento e aprimoramento de competências docentes. Os autores argumentam que a docência no ensino superior é muito mais ampla e complexa do que a atividade de ministrar aulas e propõem a tutoria (entendida como o processo de orientação e inserção de alunos no ambiente universitário) como uma importante função do professor que atua no ensino superior.

Torres e Sanchez (2008), ao se debruçarem sobre os processos de ensino e aprendizagem de adultos na pós-graduação, afirmam que a tutoria de um professor ou colega justifica-se, principalmente, em casos em que a formação inicial é deficitária.

Em um trabalho que analisou as metodologias e os resultados de um programa de autoavaliação de alunos de um programa de pós-graduação em Sistemas de Informação, na Colômbia, Rendón Giraldo (2008) demonstrou que a atividade de tutoria acadêmica (neste caso feita por professores) foi apontada pelos alunos como uma das metodologias que trouxe mais qualidade à sua formação.

O estudo de Frías (2012) sobre a relação entre a tutoria acadêmica e o desenvolvimento de um habitus científico em um grupo de estudantes de pós-graduação mexicano demonstrou que tal atividade contribuiu para que os estudantes desenvolvessem um conjunto de disposições acadêmicas que permitiram que exercessem com maior rigor sua atividade de investigadores educativos. Segundo o pesquisador, as disposições de ordem epistemológica ocuparam um lugar central, levando os estudantes a produzirem pesquisas melhores, em comparação com as produções científicas de alunos de turmas anteriores, que não tiveram contato com a tutoria.

Jimenez-Vásquez (2014) afirma que a tutoria (que compõe uma política de formação da Universidad Autónoma de Tlaxcala, México) é uma das ações que ocupam papel central na formação de estudantes de doutorado, durante o processo de planejamento e desenvolvimento de suas teses, por um tutor interno, e após a defesa, por um cotutor externo, que é responsável pelo desenvolvimento profissional dos egressos. Para a pesquisadora, essa tem sido uma das ações que intenta formar melhores professores e pesquisadores, articulando o sucesso de projetos pessoais e suas articulações com a melhoria dos contextos sociais nos quais atuam.

Em um estudo sobre o perfil de estudantes de um programa de pós-graduação em Engenharia Sonora, de uma universidade mexicana, Valdés Cuervo, Sánchez Escobedo e Yáñez Quijada (2013) demonstraram que um grupo de estudantes que participaram de um programa de tutoria acadêmica declararam-se mais satisfeitos que outro grupo que não participou do programa, em relação ao desenvolvimento de competências de investigação científica. Para eles, o grupo que participou da tutoria apresentou, ainda, melhor desempenho e produtividade acadêmica.

Os trabalhos revistos indicaram que a atividade de tutoria acadêmica constitui uma importante contribuição na formação de docentes para o ensino superior e de pesquisadores para exercerem com maior rigor a atividade de investigação científica. Tais achados muito se aproximam da experiência de tutoria relatada neste texto.

No Brasil, não encontramos nenhum estudo com esse teor. A maioria dos trabalhos refere-se a programas de Mentoria que têm entre outros objetivos a reflexão de professores sobre sua própria prática, a partir de um trabalho colaborativo com docentes "mais experientes"; e a tutoria virtual de cursos de 
graduação e pós-graduação, em que alunos e tutores estão separados espacial e até temporalmente, mas encontram-se interligados pela tecnologia. Tal modelo apresenta características diferentes do que será relatado neste texto.

Assim, revelada a escassez de estudos sobre a "tutoria acadêmica" na pós-graduação, no contexto brasileiro, enfatizamos a importância da experiência aqui relatada, tanto para a expansão dos conhecimentos, como para a sinalização da possibilidade e para a inspiração de modelos semelhantes em outras instituições de ensino superior.

\section{As características da tutoria acadêmica do curso de Mestrado Profissional em Educação: Formação de Formadores}

A tutoria acadêmica foi instituída em agosto de 2013, no início de funcionamento do Mestrado Profissional em Educação: Formação de Formadores da PUC SP. Os tutores são doutorandos dos programas de Educação: Psicologia da Educação e Educação: Currículo, da PUC-SP. Reúnem-se, no início de cada semestre, com a coordenação do Mestrado Profissional, para planejar as atividades e decidir o conteúdo e as estratégias de funcionamento da tutoria. Novas reuniões ocorrem durante o semestre para avaliação das atividades.

A tutoria consiste em encontros quinzenais dos tutores com pequenos grupos de mestrandos, com duração de uma hora, durante os dois primeiros semestres do curso. Nesses encontros, os mestrandos são orientados pelos tutores a produzir textos que os ajudem a demarcar a temática de seu Trabalho Final de Mestrado. Essa atividade é supervisionada pela professora que ministra a disciplina Pesquisa e prática reflexiva. A proposta de trabalho da tutoria tem possibilitado que os pós-graduandos - que são professores formadores - adentrem o ambiente acadêmico e conheçam sua dinâmica e as condições exigidas para a produção de um trabalho científico.

Ainda com a preocupação de inserir o mestrando no ambiente acadêmico, os tutores realizam com os mestrandos oficinas de produção de resumos e de comunicação oral e de pôster, em preparo para participação no Seminário de Práticas, uma atividade curricular que tem o propósito de divulgar relatos de experiências profissionais e de pesquisas elaboradas durante o curso.

\section{Metodologia}

Com o objetivo de analisar os significados que mestrandos e tutores atribuem à tutoria acadêmica do curso de Mestrado Profissional em Educação: Formação de Formadores, da PUC-SP, optou-se pela abordagem qualitativa de pesquisa, que, segundo André (2013, p. 97), tem como foco de atenção “[...] o mundo dos sujeitos, os significados que atribuem às suas experiências cotidianas, sua linguagem, suas produções culturais e suas formas de interações sociais".

Para a produção dos dados foi utilizado um questionário contendo três perguntas abertas: O que você destaca como mais importante no trabalho da tutoria? Quais contribuições você acha que a tutoria trouxe para você e para o seu trabalho? O que você sugere para melhorar o processo de tutoria?

Os respondentes são doutorandos dos programas de pós-graduação em Educação: Psicologia da Educação e em Educação: Currículo - os tutores -e alunos matriculados nas três primeiras turmas do Programa de Mestrado Profissional em Educação: Formação de Formadores, da PUC-SP. O questionário foi encaminhado, via Google Docs, para 116 alunos, que participaram da tutoria nos anos de 2013 e 2014, e para 13 tutores. Um total de 45 alunos e 13 tutores contribuíram com a pesquisa.

\section{Referencial Teórico}

Como se observou na revisão de literatura, os diversos trabalhos sugerem que nos programas em que a tutoria é implantada existe um ganho em termos de aprendizagem tanto para os alunos quanto para os tutores.

Tal constatação se aproxima das ponderações que fizemos a partir da organização inicial das informações coletadas, ou seja, verificamos que havia um acento nas respostas em relação à percepção de que a experiência de tutoria trouxe diferentes aprendizagens tanto para os tutorandos quanto para os tutores. Nesta direção, optamos então pelo quadro teórico defendido por Vigotski, especialmente nas discussões realizadas por ele sobre ensino, 
aprendizagem e desenvolvimento humano, sem a pretensão de esgotarmos o assunto no recorte que fizemos. Além disso, o arcabouço teórico do autor também nos permite sustentar as análises para responder nossa questão de pesquisa.

Cabe destacar que os estudos de Vigotski ${ }^{1}$ estão ancorados em seu programa geral para compreender a consciência humana. É nesta perspectiva que ao longo de sua obra, o autor investiga a relação entre pensamento e palavra, postulando que o entendimento da linguagem é a chave fundamental para a compreensão humana. $\mathrm{O}$ estudioso afirma "que a estrutura da consciência é uma estrutura semântica" (VYGOTSKY, 2004, p. 94) e o pensamento é um processo mediado, que se realiza na palavra. Para ele, o significado da palavra é, ao mesmo tempo, linguagem e pensamento, pois é "uma unidade do pensamento verbalizado" (VIGOTSKI, 2001, p. 11).

Em direção semelhante, Bakhtin e Volochínov (2006) discutem que a consciência humana só pode se desenvolver se encontrar um material concreto, flexível, veiculado pelo corpo. O signo - a palavra - traduz essa materialidade, que pode ser utilizada tanto como signo exterior quanto como signo interior: "a própria consciência humana surge e se afirma como realidade mediante a encarnação material em signos e somente no processo de interação social" (BAKHTIN; VOLOCHÍNOV, 2006, p. 33).

Assim, o mais importante de todos os sistemas simbólicos criados pela cultura humana é a linguagem, entendendo-a como constitutiva do ser humano e como principal instrumento para a mediação do homem com os conhecimentos sociais (VYGOTSKY, 2004). Nesta direção, os signos e a linguagem funcionam, ao mesmo tempo, como meio de comunicação e modo de operação mental, o que possibilita que a atividade humana seja conservada e partilhada individual e coletivamente.

Os pensamentos de Vigotski e de Bakhtin e Volochínov se aproximam, porém Vigotski (2001, p.

1 Neste artigo usaremos a grafia "Vigotski", com “i”. Tomamos tal decisão uma vez que utilizamos várias versões das obras deste autor. As primeiras traduções, editadas no Brasil pela Martins Fontes, utilizavam a grafia "Vygotsky". A partir da década de 90 do século passado, passaram a adotar a grafia Vigotski. A edição espanhola das obras completas (Visor) utiliza "Vygotski" e a edição em inglês utiliza "Vygotsky". Finalmente, Prestes (2012) adotou a grafia "Vigotski", com a qual nos alinhamos. A exceção é feita à referência. Neste caso utilizamos a grafia constante no título da obra.
409) faz uma ressalva de que a palavra não revela o pensamento numa relação direta, pronta e acabada, uma vez que "a relação entre o pensamento e a palavra não é uma coisa, mas um processo, um movimento do pensamento à palavra e da palavra ao pensamento".

Como discute Vigotski (2001, p. 409) "O pensamento não se exprime na palavra, mas nela se realiza". Uma palavra, um signo, contém tanto o sentido (pessoal) como o significado (social) em constante tensão dialética.

Assim, entendemos que para a apreensão do pensamento do indivíduo é necessário considerar, ainda, que esse pensamento sofre muitas transformações para ser expresso em palavras, e a transição do pensamento para a palavra, por sua vez, passa pelo significado e pelo sentido. Para elucidar melhor a relação entre pensamento e palavra, utilizaremos as categorias sentido e significado, considerando que, pelo objetivo proposto nesta pesquisa, tornam-se essenciais.

Cabe esclarecer que os sentidos são mais pessoais, trazidos pelos indivíduos a partir de sua história e experiências, e nos deixam entrever seu modo de pensar, sentir e agir. Já os significados são mais estáveis e dicionarizados, permitindo a comunicação e a socialização das experiências vividas. No contato com o outro e em contextos de atividade intencional (como são os espaços de tutoria), os indivíduos trazem para o grupo seus sentidos, ou seja, partilham experiências, afetos e emoções. $\mathrm{Na}$ relação mútua, os sentidos podem ser expandidos e ressignificados.

É importante relembrar que, nessa perspectiva, não há separação entre pensamento e afeto, pois ambos estão dialeticamente articulados, e o pensamento é sempre emocionado, o que implica que desconsiderar a dimensão afetiva/emocional impossibilitaria a explicação das causas do próprio pensamento. Nas palavras de Vigotski (2001, p. 15-16, grifo nosso):

Quando falamos da relação do pensamento e da linguagem com os outros aspectos da vida da consciência, a primeira questão a surgir é a relação entre o intelecto e o afeto. Como se sabe, a separação entre a parte intelectual de nossa consciência e a parte afetiva volitiva é um dos defeitos radicais de toda a psicologia tradicional [...] Quem separou desde o 
início o pensamento do afeto fechou definitivamente para si mesmo o caminho para as causas do próprio pensamento, porque a análise determinista do pensamento pressupõe necessariamente a revelação dos motivos, necessidades, interesses, motivações e tendências motrizes do pensamento que lhe orientam neste ou naquele aspecto.

Como apontado acima, a análise do pensamento implica aspectos afetivos e volitivos e pressupõe necessariamente a revelação das emoções, dos motivos, necessidades e interesses que orientam o seu movimento. Por trás do pensamento existe uma tendência afetiva e volitiva. "Só ela pode dar a resposta ao último porquê na análise do pensamento. [...] A compreensão efetiva e plena do pensamento alheio só se torna possível quando descobrimos a sua eficaz causa profunda afetivo-volitiva" (VIGOTSKI, 2001, p. 479-480).

Ainda estreitamente relacionado à discussão sobre os sentidos e significados, Vigotski (2001) aprofundou a investigação sobre a aprendizagem humana e distinguiu os conceitos espontâneos - que são adquiridos na experiência cotidiana e espontânea do indivíduo com o seu meio - dos conceitos científicos, introduzidos na educação formal. O autor atribuiu o nível maior de consciência dos conceitos científicos ao fato de serem produzidos em colaboração sistemática entre o professor/educador e o aprendiz. (VIGOTSKI, 2001).

É nesse âmbito que ele introduz o conceito de Zona de Desenvolvimento Proximal (ZDP), para defender que a relação intencional entre o professor e o aprendiz é um fator determinante para a aprendizagem. Em suas palavras destaca que: "O que hoje a criança faz com auxilio poderá fazer amanhã por conta própria" (VYGOTSKY, 2004, p. 480).

Partindo deste arcabouço, Magalhães (2008) explica que o conceito de ZDP não representa apenas a apropriação de conhecimentos com a ajuda do outro, mas se define como uma relação que se estabelece para o desenvolvimento integral da pessoa. Ou nas palavras do próprio Vigotski (2001, p. 331): "o desenvolvimento decorrente da colaboração [...] é a fonte do surgimento de todas as propriedades especificamente humanas da consciência."

Contribuindo com a discussão, Newman e Holzman (2002) definem a ZDP como a unidade de aprendizagem e desenvolvimento por excelência, enquanto para Magalhães (2009) a ZDP é uma zona de ação criativa, uma atividade prático-crítica apoiada na colaboração e na reflexão crítica mútua.

Para John-Steiner (2000, p. 187), "contextos colaborativos fornecem uma zona de desenvolvimento proximal mútua na qual os participantes podem aumentar o seu repertório de expressão cognitiva e emocional”. Isso significa que uma ZDP mútua favorece a possibilidade de indivíduos aprenderem uns com os outros e se constitui num espaço de crescimento em que cada participante pode ouvir o outro e também ouvir-se por outra perspectiva. Por meio dessa colaboração, impulsiona o desenvolvimento de todos os envolvidos.

\section{O Processo e a fundamentação da análise dos dados}

Para a análise das informações, inspiramo-nos na metodologia dos "Núcleos de Significação" (AGUIAR; OZELLA, 2006, 2013). Para a discussão dos resultados, nos basearemos tanto na revisão da literatura quanto nos trabalhos de Vigotski, pois, como já pontuamos, entendemos que as significações representam a síntese da objetividade e da subjetividade.

Inicialmente, fizemos uma leitura exaustiva das respostas, procurando identificar os temas mais frequentes e questões recorrentes. Para isso, selecionamos as expressões ou as chamadas "palavras com significado", ou seja, uma palavra qualificada/ adjetivada pelo sujeito respondente, à qual ele atribui uma propriedade". A partir do conjunto do material disponível, procedemos à identificação da(s) palavra(s) com significado, ou seja, da(s) palavra(s) inserida(s) em um contexto, que será(ão) chamada(s) de pré-indicador(es);

Cabe destacar que num primeiro momento categorizamos separadamente as respostas dos alunos e tutores. A leitura das informações indicou que elas continham muitas semelhanças. Desta maneira, num movimento posterior, agrupamos os pré-indicadores em indicadores, e nesta organização já consideramos respostas tanto dos alunos como dos tutores. Finalmente, realizamos a organização dos indicadores em núcleos de significação.

Decidimos construir núcleos com as vozes de alunos e tutores, uma vez que as análises prelimina- 
res sinalizavam que ambos os públicos apontavam fortemente a aprendizagem que tiveram, participando do processo de tutoria. Exemplificaremos cada um destes movimentos.
As palavras com significado (AGUIAR; OZELLA, 2006), ou seja, a escolha lexical qualificada, foram negritadas, conforme o exemplo a seguir:

\section{A) Identificação dos pré-indicadores}

Acompanhamento e Orientações para delimitação do tema. (aluno).

As orientações e a partilha de experiências. (tutor).

As intervenções feitas pelos tutores a partir do que levamos de produção. (aluno).

Em seguida, procuramos agrupar esse conjunto de palavras (e/ou frases) que apresentavam semelhanças e nomeamos esse conjunto de "indicadores" que expressavam um determinado conteúdo temático.
Esse procedimento foi adotado, inicialmente, para cada uma das respostas dos sujeitos participantes da pesquisa: A(Aluno), T (Tutor), conforme quadro a seguir.

B) Organização dos pré-indicadores em indicadores

\begin{tabular}{|l|l|}
\hline Pré-indicadores (escolhas lexicais - palavras com significado) & Indicadores - conteúdo temático \\
\hline $\begin{array}{l}\text { Acompanhamento e Orientações para delimitação do tema. (A) } \\
\text { As orientações e a partilha de experiências. (A) } \\
\text { Compartilhamento de ideias. (T) }\end{array}$ & $\begin{array}{l}\text { Acompanhamento e orientação } \\
\text { em relação ao projeto }\end{array}$ \\
$\begin{array}{l}\text { As intervenções feitas pelos tutores a partir do que levamos de } \\
\text { produção. (A) }\end{array}$ & $\begin{array}{l}\text { O grande interesse em ajudar. (A) } \\
\text { A consideração em relação ao outro. (T) } \\
\begin{array}{l}\text { Todo o apoio oferecido pelos tutores. (A) } \\
\text { A disponibilidade e generosidade dos tutores. (A) } \\
\text { A atenção e o suporte. (A) }\end{array}\end{array}$ \\
$\begin{array}{l}\text { No momensideração e } \\
\text { correções, ou seja, o que precisa ser melhorado no texto. (A) } \\
\text { A parceria que os tutores estabeleceram com os discentes na } \\
\text { leitura dos textos e orientações. (A) } \\
\begin{array}{l}\text { Escutar os mestrandos e tomar como ponto de partida do } \\
\text { trabalho de tutoria os saberes que eles trazem consigo e desejam } \\
\text { superar/aprofundar. (T) } \\
\text { A colaboração na orientação e acompanhamento de } \\
\text { profissionais da educação que estão no processo de inserção na } \\
\text { vida acadêmica. (T) }\end{array}\end{array}$ & $\begin{array}{l}\text { Parceria, colaboração e } \\
\text { atenção individualizada }\end{array}$ \\
\hline
\end{tabular}


Desafiador participar com o tutorando das definições de seu objeto de investigação. (T)

Eu aprendo muito com essa atividade! (T)

Desafios e aprendizagem

A aprendizagem profissional. (T)

A organização final dos indicadores nos permitiu constituir um núcleo de significação intitulado "A tutoria como uma ZPD", que analisaremos a seguir.

\begin{tabular}{|l|l|}
\hline Núcleo de significação & Indicadores \\
\hline \multirow{2}{*}{ A Tutoria como uma ZPD. } & $\begin{array}{l}\text { Acompanhamento e orientação em relação ao projeto. } \\
\text { Interesse, consideração e apoio mútuo. } \\
\text { Parceria, colaboração e atenção individualizada. } \\
\\
\text { Desafios e aprendizagem. }\end{array}$ \\
\hline
\end{tabular}

\section{Núcleo de significação: A tutoria como uma} ZDP

Este núcleo permite discutir a atividade de tutoria como um lócus/espaço constituinte de aprendizagem tanto para os tutores como para os alunos, em que a colaboração e o interesse mútuo num empreendimento comum emergem como definidores do respeito e da aprendizagem resultante da experiência. Vejamos:

Como não tinha experiência na docência do ensino superior, a tutoria me possibilitou entrar em contato com as dificuldades experimentadas pelos discentes que ingressam na pós-graduação. Fora este ponto, destaco o trabalho em grupo com outros colegas. A troca de experiência na elaboração das atividades, com os colegas da pós-graduação, e no trabalho, com os alunos, foi um ponto muito positivo. (Tutor 12).

O destaque na fala acima evidencia a importância da atividade para o tutores e sugere a relevância do trabalho em colaboração. Em direção semelhante observa-se também que o trabalho em grupo entre os colegas tutores parece converter-se em suporte para enfrentar os desafios nesta dimensão da prática acadêmica.
Além disso, os tutores destacaram no trabalho da tutoria a possibilidade de compartilhar saberes e experiências; ser parceiro "mais experiente" dos colegas que iniciaram a pós stricto sensu; e entrar em contato com as dificuldades experimentadas pelos pós-graduandos e auxiliá-los no processo de elaboração do trabalho de conclusão de curso, como podemos observar nos exemplos a seguir:

A oportunidade de compartilhar experiências com profissionais que trazem diferentes experiências da educação básica, e que têm um objetivo em comum: investigar e (re) significar a própria prática. (Tutor 9).

Atenção e suporte inicial para o encaminhamento de dúvidas e angústias do aluno iniciante na vida acadêmica. (Tutor 3).

Acredito que a construção/discussão dos encaminhamentos de pesquisa dos alunos. Penso também que o acolhimento é fundamental para o acompanhamento/desenvolvimento do trabalho de pesquisa. (Tutor 2).

O trabalho da tutoria tem dois lados que merecem destaque. O primeiro, que eu considero fundamental, é os alunos terem acompanhamento de parceiros um pouco 'mais experientes' num curso de pós strictu sensu, que pelas características, é absolutamente 
solitário. Acredito que a tutoria minimize a solidão e faz com que seus participantes sintam-se menos estrangeiros nos caminhos que resolveram trilhar. (Tutor 5).

Como discutido por Bastos e colaboradores (2011), a docência no ensino superior é muito mais complexa do que a atividade de ministrar aulas. As respostas acima colaboram para a interpretação de que a tutoria está sendo significada como o processo de orientação e inserção de alunos no ambiente universitário e de preparação para a docência no ensino superior.

Quanto às contribuições trazidas pela tutoria para os tutores e seu trabalho, observa-se, além da aproximação com diferentes práticas educativas, aspectos afetivos envolvidos na parceria, como laços de amizade, e a aprendizagem decorrente do compartilhamento de objetivos comuns. Vejamos os exemplos a seguir:

Ao longo do tempo fortalecemos laços de amizade ao ponto em que uma aluna participante da tutoria, sabendo do meu objeto de investigação do doutorado, encontrou um texto correlato à minha pesquisa e fez questão de compartilhar. Eu aprendo muito com essa atividade! (Tutor 5).

Tal declaração nos orienta a não desconsiderar a dimensão afetiva/emocional, que impossibilitaria a explicação das causas do sucesso deste tipo de tutoria: "O apoio, as dicas de caminhos pelos quais percorrer; tudo isso serve como incentivo" (tutorando).

$\mathrm{O}$ afeto, nesse sentido, significa a possibilidade de impactar e afetar a vida de outros, promovendo a possibilidade de reorganização de sentidos e significados sobre uma dada situação ou seja, promover o desenvolvimento. Cabe ressaltar que aqui também não se percebe separação entre pensamento e afeto, uma vez que ambos estão dialeticamente articulados e o pensamento é sempre emocionado. (VIGOTSKI, 2001, p. 12).

Tais percepções são encontradas também nas respostas dos alunos.

Todos os discentes, sem nenhuma exceção, declararam a importância da tutoria para o seu aprendizado e destacaram um conjunto de aspectos para justificar sua afirmação, que podem ser divididos em dois grupos.
O primeiro está relacionado às contribuições dessa atividade para o desenvolvimento do projeto de dissertação do mestrado, como: o auxílio na definição do tema para estudo; orientações quanto ao desenvolvimento das etapas da pesquisa; e as trocas entre tutores e discentes que permitiram diferentes olhares para os diversos temas, como podemos constatar nos excertos abaixo:

Atender e orientar os alunos ingressantes nos seus períodos iniciais da pós graduação. (Aluno 16).

[...] a devolutiva a partir da leitura de $\mathrm{O}$ tema e eu. ${ }^{2}$ (Aluno 18).

O segundo grupo evidencia aspectos referentes ao próprio trabalho dos tutores, como: o interesse, a disponibilidade e generosidade; a boa formação dos tutores; e a partilha de experiências.

Como a maioria dos tutores já está no doutorado, a contribuição desse grupo com orientações para a nossa pesquisa foi muito valiosa. (Aluno 6).

As práticas dos tutores facilitam o envolvimento discente nas pesquisas. (Aluno 12).

Momentos ricos de troca de experiência e ampliação de perspectivas referente a temática escolhida para estudo (diferentes focos de análise) e na busca de referencial bibliográfico. (Aluno 32).

Cabe ressaltar que momentos "ricos de troca de experiências" e "ampliação de perspectivas" são constituídos também por dinâmicas intencionalmente pensadas em que os participantes podem escutar o outro e escutar a si próprios de outra perspectiva. Em suma, alunos e tutores expressam suas significações sobre o projeto, sobre as experiências vividas em grupo, assim como acerca dos objetivos da tutoria. Cabe ressaltar, ainda, que o fato de compartilharem um espaço de reflexão conjunta, possibilitou a todos o alcance de novas compreensões sobre o que se discutia.

As afirmações indicam que os espaços de tutoria, a frequência com que ocorrem e a organização das discussões sugerem que as trocas dialógicas entre os participantes permitiam que cada um trouxesse para o debate os seus sentidos sobre o ambiente e exigências acadêmicas, e no contato com

$2 \mathrm{O}$ texto "O tema e eu" refere-se à primeira atividade realizada pelos alunos do Mestrado Profissional para o início da delimitação do objeto de estudo. 
os outros elas fossem ressignificadas, expandindo a compreensão (VYGOTSKY, 2004).

Isso pode ser observado também em relação às contribuições da tutoria para o trabalho de conclusão de curso. Os alunos assinalaram dois pontos que merecem destaque: o primeiro refere-se ao acompanhamento dos tutores na elaboração do projeto de pesquisa (leitura das produções; auxílio na delimitação do objeto de investigação; indicações de leitura; e apresentação dos caminhos para busca de referências, além das dicas de produção textual), conforme ilustra o depoimento a seguir:

Muitas contribuições foram importantes na trajetória dos encontros de tutoria, [...] como por exemplo: a questão do acolhimento nos momentos difíceis, sempre trazendo uma palavra de apoio e direcionamento de forma positiva. Já com o trabalho de pesquisa, o passo a passo da construção da dissertação, principalmente no aspecto metodológico, foi fundamental. (Aluno 19).

O segundo ponto indica uma contribuição que perpassa o campo científico e refere-se ao incentivo para realização da pesquisa, e o fato de os tutores terem facilitado o envolvimento dos discentes com o trabalho de conclusão do curso.

Para melhorar o processo de tutoria, os alunos participantes do estudo indicaram a necessidade de diminuir o número de alunos por grupo de tutores; alinhar melhor o trabalho da tutoria, pois evidenciaram-se posturas diferentes na condução das orientações; e ampliar o tempo da atividade de tutoria para se tornar semanal.

$\mathrm{O}$ entrelace entre as frases que carregam os significados atribuídos para a tutoria tanto dos tutores como dos alunos sugere que ambos os públicos mostram a relação desenvolvida, o compromisso com o projeto, a escuta atenta, a aprendizagem como uma marca. Durante os encontros efetivou-se a produção de uma situação em que todos aprendem. Nesta direção, as análises indicam que se instaurou um espaço colaborativo e que foi possível a aprendizagem e o desenvolvimento (VIGOTSKI, 2001).

Assim, entendemos que se formou, como aponta John-Steiner (2000, p. 187), um "contexto colaborativo que se converteu numa zona de desenvolvimento proximal mútua na qual os participantes puderam aumentar o seu repertório de expressão cognitiva e emocional”. Este espaço, criado dialogicamente, foi lócus para os participantes se constituírem acadêmicos em diferentes papéis, e para a possibilidade de indivíduos constituírem um espaço de crescimento em que cada participante pôde ouvir o outro e também ouvir-se por outra perspectiva.

\section{Considerações finais}

Os resultados iniciais apontam que a tutoria se constituiu num espaço de aprendizagem que possibilitou o desenvolvimento para ambos os públicos. Podemos inferir que para os alunos do mestrado profissional se observou um salto significativo no que se refere à sua formação acadêmica. Já para os tutores, esse salto se refere a um desenvolvimento profissional mais direcionado para a docência no ensino superior e para a aprendizagem da orientação acadêmica. Essa observação, porém, não exclui outras aprendizagens (do ponto de vista do desenvolvimento profissional e acadêmico) que ambos os públicos possam ter tido.

Concluímos que os espaços de tutoria converteram-se em um empreendimento colaborativo, ou seja, numa Zona de Desenvolvimento Próximo (ZDP), entendida como uma zona de confiança, mas também de conflitos, em que os participantes compartilharam a produção do conhecimento por meio de sentidos e significados construídos e reconstruídos constantemente nos espaços de discussão organizados nas tutorias quinzenais. Como aponta John-Steiner (2000), em empreendimentos colaborativos, a apropriação mútua é o resultado de um engajamento sustentado, durante o qual os participantes escutam, discordam e lutam para alcançar os pensamentos e as ideias dos outros, num movimento que não é apenas um processo cognitivo, mas sim apropriação intelectual e emocional.

Assim, entendemos que o construto da ZPD, mais do que um fator a se observar no modo como cada pessoa aprende, pode ajudar também a compreender como coletivos de pessoas aprendem e foi bastante significativo para compreender o processo de aprendizagem mútuo que foi reportado pelos participantes e indicativo do que ocorreu na tutoria. 
Em que pese a necessidade de mais pesquisas sobre esta experiência e a necessidade de aprofundar este debate que aqui se inicia, destacamos que a atividade de tutoria acadêmica tem contribuído positivamente, no âmbito do Mestrado Profissional em Educação: Formação de Formadores, tanto para o aprendizado e formação de novos pesquisadores quanto de docentes e orientadores para o ensino superior.

\section{REFERÊNCIAS}

AGUIAR, W. M. J.; OZELLA, S. Apreensão dos sentidos: aprimorando a proposta dos núcleos de significação. Revista Brasileira de Estudos Pedagógicos, Brasília, DF, v. 94, n. 236, p. 299-322, jan./abr. 2013.

. Núcleos de significação como instrumento para a apreensão da constituição dos sentidos. Psicologia: Ciência e Profissão, Brasília, DF, v. 26, n. 2, p. 222-245, jun. 2006.

ANDRÉ, M. O que é um estudo de caso qualitativo em educação? Revista da FAEBBA - Educação e Contemporaneidade, Salvador, v. 22, n. 40, p. 95-103, 2013.

ARNAIZ, P. Fundamentação da tutoria. In: ARGÜIS, R. et al. Tutoria. Com a palavra, o aluno. Porto Alegre: Artmed, 2002. p. 15-24. (Coleção Inovação Pedagógica, v. 6).

BAKHTIN, M; VOLOCHÍNOV, V. N. Marxismo e Filosofia da Linguagem. São Paulo: Hucitec, 2006.

BASTOS, A. V. B. et al. Réplica 1 - formar docentes: em que medida a pós-graduação cumpre esta missão? Revista de Administração Contemporânea, Curitiba, v. 15, n. 6, p. 1152-1160, nov./dez. 2011.

BORDIEU, P.; PASSERON, J. C. Os herdeiros. Os estudantes e a cultura. Florianópolis: Editora da UFSC, 2014. DURAN, D.; VIDAL, V. Tutoria. Aprendizagem entre iguais. Porto Alegre: Artmed, 2007.

FRÍAS, J. de la C. T. El papel de la tutoría em la formación de habitus científicos em estudiantes de doctorado em educación. 2012. Disponível em: $<$ http://www.publicaciones.cucsh.udg.mx/pperiod/cgraduados/pdf/2012/ el_papel_de_la_tutoria.pdf $>$. Acesso em: 02 jun. 2015.

JIMENEZ-VÁSQUEZ, M. S. Trayectorias profesionales de egresados del Doctorado em Educación de la Universidad Autónoma de Tlaxcala: Unanálisis de las funciones, productividad y movilidad e nel mercado académico. Perfiles Educativos, v. 36, n. 143, p. 30-48, 2014.

JOHN-STEINER, V. Creative collaboration. New York: Oxford University Press, 2000.

MAGALHÃES, M. C. C. O método para Vygotsky: a Zona Proximal de Desenvolvimento como zona de colaboração e criticidade criativas. In: SCHETTINI, R. et al. (Org.). Vygotsky: uma revisita no início do século XXI. São Paulo: Andross, 2009. p. 53-78.

MARTINS, C. B. A reforma universitária de 1968 e a abertura para o ensino superior privado no Brasil. Educação e Sociedade, Campinas, SP, v. 30, n. 106, p. 15-35, jan./abr. 2009. Disponível em: <http://www.scielo.br/pdf/es/ v30n106/v30n106a02>. Acesso em: 13 mar. 2016.

NEWMAN, F; HOLZMAN, L. Lev Vygotsky: cientista revolucionário. São Paulo: Loyola, 2002.

PASSOS, L. F.; PEREIRA, R.; PRINCEPE, L. M. As condições de trabalho como fatores constituintes da profissionalidade docente de professores iniciantes dos cursos de licenciatura. In: SEMINÁRIO DE EDUCAÇÃO BRASILEIRA, 5., 2015, Campinas, SP. Anais... Campinas, SP: CEDES, 2015.

PRESTES, Z. Quando não é quase a mesma coisa: traduções de Lev Semionovitch no Brasil. Campinas, SP: Autores Associados, 2012.

RENDÓN GIRALDO, N. E. Proceso de autoevaluación de posgrado: proceso de autoevaluación de posgrado: aplicación de una metodología. Revista Interamericana de Bibliotecología, v. 31, n. 1, p. 135-160, jan./jun. 2008.

ROLDÃO, M. C. Gestão curricular - fundamentos e práticas. Lisboa: ME-DEB, 1999.

SGUISSARDI, V. (Org.). Universidade brasileira no século XXI. São Paulo: Cortez, 2009.

VALDÉS CUERVO, A. A.; SÁNCHEZ ESCOBEDO, P. A.; YÁÑEZ QUIJADA, A. I. Perfiles de estudiantes mexicanos com aptitudes intelectuales sobresalientes. Acta Colombiana de Psicología, Bogotá, v. 16, n. 1, p. 25-33, 
2013. Disponível em: <http://www.redalyc.org/articulo.oa?id=79829185003>. Acesso em: 02 jun. 2015.

VALLE, I. R. Por que ler Os Herdeiros meio século depois? In: BORDIEU, P., PASSERON, J. C. Os herdeiros. Os estudantes e a cultura. Florianópolis: Editora da UFSC, 2014. p. 9-13.

VIGOTSKI, L. S. A construção do pensamento e da linguagem. São Paulo: Martins Fontes, 2001.

VYGOTSKY, L. S. O método instrumental em Psicologia. In: Martins Fontes, 2004. p. 93-101. . Teoria e método em Psicologia. São Paulo:

Recebido em: 14/07/2016

Aprovado em: 15/09/2016 